\title{
A New Phantom for Individual Verification of the Dose Distribution in Precision Radiotherapy for Head-and-Neck Cancer
}

\author{
MELANIE GREHN $^{1}$, MAIK STILLE ${ }^{2}$, CHRISTIAN ZIEMANN ${ }^{1}$, \\ FLORIAN CREMERS ${ }^{1}$, DIRK RADES ${ }^{1}$ and THORSTEN M. BUZUG ${ }^{2}$ \\ ${ }^{1}$ Department of Radiation Oncology, University of Lübeck, Lübeck, Germany; \\ ${ }^{2}$ Institute of Medical Engineering, University of Lübeck, Lübeck, Germany
}

\begin{abstract}
Background/Aim: Many patients with head-andneck cancers receive radiotherapy. Treatment planning can be very complex in case of dental fillings or implants that cause metal artefacts. Verification of dose distributions may be performed using specific phantoms. This study aimed to develop a 3D-printed phantom that can be produced easily and cost-effectively. Patients and Methods: The phantom was designed to allow fast adaption to a patient's individual situation with a particular focus on metal artefacts due to dental fillings. Bone and soft-tissue shells were $3 D$-printed and filled with tissue-equivalent materials. Results: Attenuation properties of the tissue-equivalent structures in the phantom corresponded well to the structures of real human anatomy. In magnetic resonance (MR)-imaging, useful signals of the materials in the phantom were obtained. Conclusion: The phantom met the requirements including equivalence with human tissues and can be useful for highly individual treatment planning in precision-radiotherapy of head-and-neck cancers. It can be also used for scientific issues related to MR-imaging.
\end{abstract}

The number of patients with head-and-neck cancer is constantly increasing (1). Most patients with locally advanced tumors receive radiotherapy alone or following surgery. Since comparatively high radiation doses of 60-70 Gy are generally required, the treatment can be associated with significant acute and late toxicities (2-5). These toxicities include xerostomia,

This article is freely accessible online.

Correspondence to: Melanie Grehn, MSc., Department of Radiation Oncology, University of Lübeck, Ratzeburger Allee 160, 23562 Lübeck, Germany. Tel: +49 45150045401, Fax: +49 45150045404, e-mail:melanie.grehn@uksh.de

Key Words: Head-and-neck cancer, precision-radiotherapy, treatment planning, individualization, dosimetry, phantom. which can be burdensome for the patients and lead to late sequelae such as radiation caries (6). Xerostomia following radiotherapy can be reduced with the use of modern precision techniques such as intensity-modulated radiotherapy (IMRT) and volume-modulated arc therapy (VMAT) $(6,7)$. In order to provide the optimal radiation treatment for a head-and-neck cancer patient, the patient's individual situation including his anatomy must be appropriately considered. Treatment planning and delivery become more complex if a patient has dental fillings and implants or titanium implants as part of reconstructive surgery (8). Particularly, verification of the distribution of the radiation dose, which is an important procedure of quality assurance in radiation oncology, can become very difficult. Usually, the verification is performed at the linear accelerator (LINAC) without the patient. The calculated dose distribution of the treatment plan and the dose distribution measured at the LINAC using the attached imaging system are compared. In case of dental fillings or implants, this way of conventional verification of the dose distribution is less precise. Fillings and implants absorb radiation leading to deviations of the dose distribution, which cannot be appropriately considered during conventional verification. In these situations, verification may be performed with a specific phantom for dosimetric measurements, which considers the individual situation of a specific patient.

Phantoms are already commercially available for quality assurance purposes in radiation therapy. However, these phantoms cannot be adapted to a patient's individual situation. Moreover, they are comparatively expensive. Due to the fast development of rapid prototyping, it recently has become possible to produce phantoms that can take into account specific requirements for individual patients and can be produced at reasonable costs. The present study aimed to develop a new phantom specifically for head-and-neck cancer patients, which considers the impact of metal artifacts caused by dental fillings on the distribution of the radiation dose in these patients (9-11). 


\section{Patients and Methods}

Requirements. The phantom had to be anthropomorphic. In addition, the use of various dosimetry procedures should be practicable. Moreover, it should be possible to adapt the phantom quickly and cost-effectively to various individual situations. To meet these requirements, the phantom should not be built as one piece but in layers. This means that all required changes will affect only one or very few layers but not the whole phantom. As a result, it would not be required to rebuild the whole phantom for each different situation. The layered structure of the phantom would also allow the placement of radiochromic films in the interlayer spaces. These films allow dose measurements and comparisons with planned dose distributions (12). Due to the layer arrangement, fixing options must be created for the stabilization of the phantom and its reproducible storage.

A clinically relevant aspect that needs to be addressed by the phantom is the influence of metal artifacts caused by dental implants and fillings on the real dose distribution in radiotherapy of head-and-neck cancer patients. Therefore, the teeth of the phantom should be exchangeable easily and fast. This would ensure that measurements can be carried out, with or without metallic fillings, without major modifications of the phantom. The phantom should be usable for various issues related to the dose distribution of external beam radiotherapy, brachytherapy and stereotactic radiotherapy (13-18). Moreover, it should be usable for magnetic resonance (MR)-imaging.

Testing of the material. The material for the construction of the phantom should meet two requirements, i.e. physical properties equivalent to human tissue considering attenuation coefficients and Hounsfield units (HU) and an easy and fast manufacturing process. In the preliminary stages of the construction process, different materials were tested with respect to processing and attenuation properties. For these tests, a computer tomograph (CT) (Siemens Somatom Balance, Siemens AG, Erlangen, Germany) was used. Data acquisition was performed with the following device settings: image matrix of $512 \times 512$, tube voltage of $130 \mathrm{kV}$, tube current of $34 \mathrm{~mA}$, exposure time of $1500 \mathrm{msec}$, focus size of $0.95 \mathrm{~mm}$, slice thickness of $3 \mathrm{~mm}$ and the reconstruction kernel B30s. As bone equivalent, conventional gypsum plaster (Modellgips für Bau und Hobby, decotric $\mathrm{GmbH}$, Hann. Muenden, Germany) was tested. The gypsum plaster used was mixed with water (2:1). After $24 \mathrm{~h}$, the gypsum plaster was completely cured and dried. The generated CT-images were evaluated using ImageJ (https://imagej.nih.gov/ij/). There was a pixel-by-pixel analysis within a region of interest (ROI) $(26.52 \times 12.88)$ and the calculation of a mean $\mathrm{HU}$ value. As tissue equivalent, three different materials were tested for their suitability: two-component silicone rubber (Sidopal Abformsilikon 8130-T, Fiberglas Discount GmbH, Hohenbrunn, Germany), two-component polyurethane casting resin (Polyurethan Giessharz Resinpal 1818, Fiberglas Discount GmbH, Hohenbrunn, Germany) and construction silicone (MEM Universal Silikon, Bauchemie GmbH, Leer, Germany).

Development of the phantom. The basis for the manufacturing of the phantom was a CT-dataset of the X-CAT software phantom (19). The dataset corresponded to a male adult with minor anatomical simplifications. The image pixels contain information about the attenuation values $\mu$. For further processing Hounsfield units were required.
Therefore, the dataset was read into MATLAB (The MathWorks, Inc., Natick, MA, USA, Version: R2015a, ReadData3D: D. Kroon, University of Twente, 2010) and the

$$
H U_{\text {tissue }}:=\frac{\mu_{\text {tissue }}-\mu_{\text {water }}}{\mu_{\text {water }}} \cdot 1000 \mathrm{HU}
$$

Hounsfield units were calculated pixel by pixel. The row of pixels separating the upper and lower rows of teeth was used as baseline to divide the entire dataset into layers. This resulted in eleven $2 \mathrm{~cm}-$ layers and one $3 \mathrm{~cm}$-layer. For extracting individual structures from the CT images, a 3D modeling software was required, which enabled subsequent storage of the structures in a readable format for a 3D printer. The open source program 3D Slicer [Open Source Initiative, Palo Alto, USA, (20)] was used for segmentation of the surface and the bone shell of the corresponding layers with the following threshold values $\mathrm{T}$ :

$$
T_{\text {bone }}(H U)= \begin{cases}0, & H U<200 \\ 1, & H U \geq 200\end{cases}
$$

and

$$
T_{\text {tissue }}(H U)=\left\{\begin{array}{ll}
0, & H U<-100>10 \\
1, & -100 \leq H U \geq 10
\end{array} .\right.
$$

The low HU-limit for the soft tissues resulted from the fact that only the surface should be segmented and not the complete soft tissue area.

Based on a surface triangulation, the different segmentations were stored in a stereo-lithography (stl) format. When creating stlfiles from anatomical structures, free triangulations and incorrectly closed surface sections may occur due to the irregular surface structure, which require further processing. Using the open source software Blender (Stichting Blender Foundation, Amsterdam, the Netherlands), holes in the structure were closed and free triangulations eliminated. In addition, a simple smoothing filter was used. With this filter, the triangulations could be smoothened by flattening the angles between adjacent faces.

The printed bone shells (Figure 1) were filled with bone equivalent material and combined with the corresponding printed surface. Subsequently, the combined layer was filled with tissueequivalent material. Air-filled anatomical structures such as the trachea and paranasal sinuses were simulated with silicone rubber. This could be removed without residue after curing of the tissueequivalent material (Figure 2).

To study the influence of metal artifacts due to dental fillings, a CT-dataset of a conventional dental model was generated (Siemens Somatom Balance, matrix of $512 \times 512$, tube voltage of $130 \mathrm{kV}$, tube current of $90 \mathrm{~mA}$, exposure time of $1500 \mathrm{msec}$, focus size of 0.6 $\mathrm{mm}$, slice thickness of $1 \mathrm{~mm}$ and reconstruction kernel H80s). The dataset was processed as described above and printed twice. The dental model was filled with a combination of conventional plaster and pure calcium phosphate. One dataset served as reference. The other one was processed to fill drill holes with lead as an equivalent to amalgam fillings (Figure 3).

To be able to assess the phantom for further validation after completion of the manufacturing process, CT and MRI datasets 


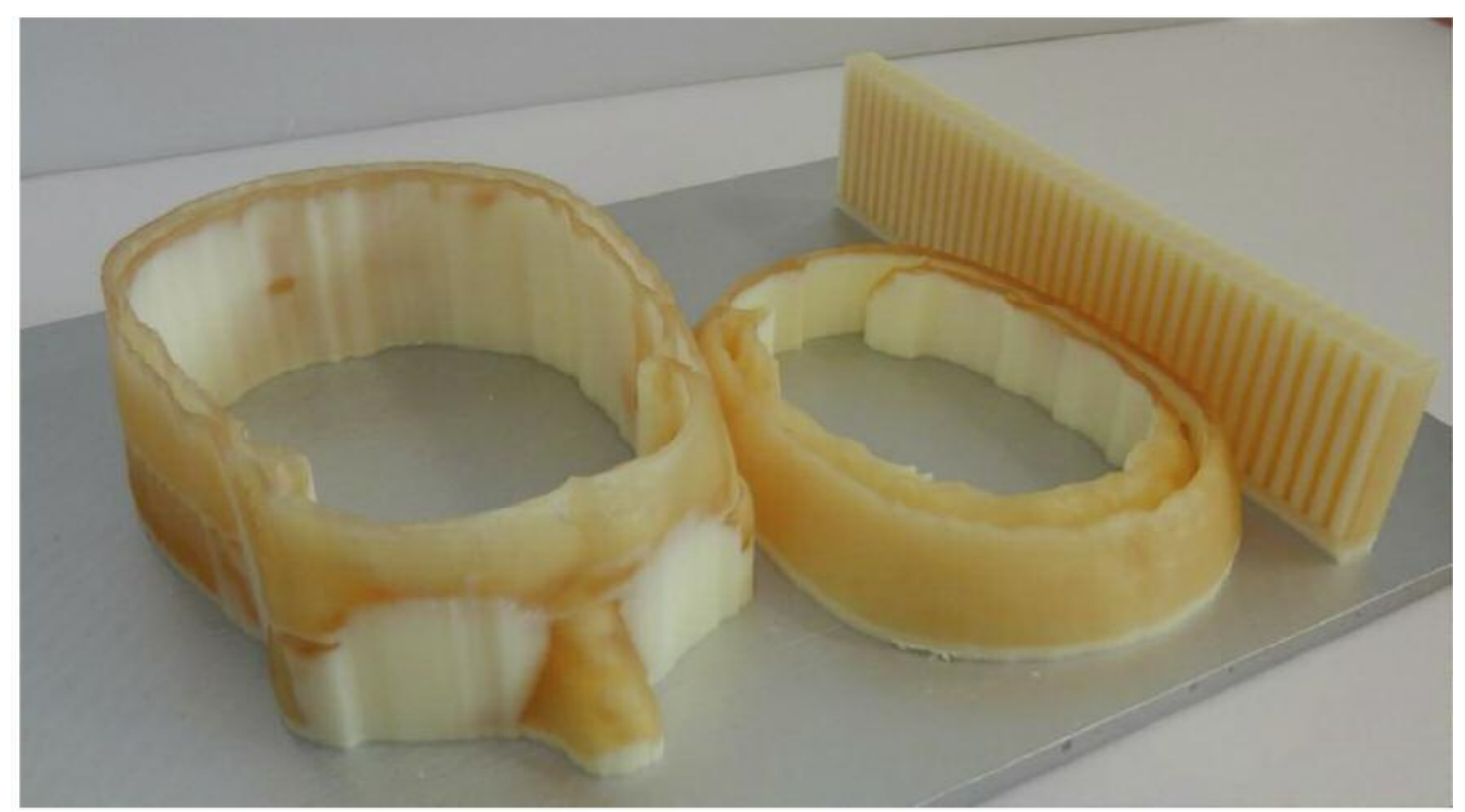

Figure 1. Three 3D-printed bone slices that corresponded to layers 3 to 5 of the phantom. After additive manufacturing the bone slices still contained supporting material (white), which was removed later.

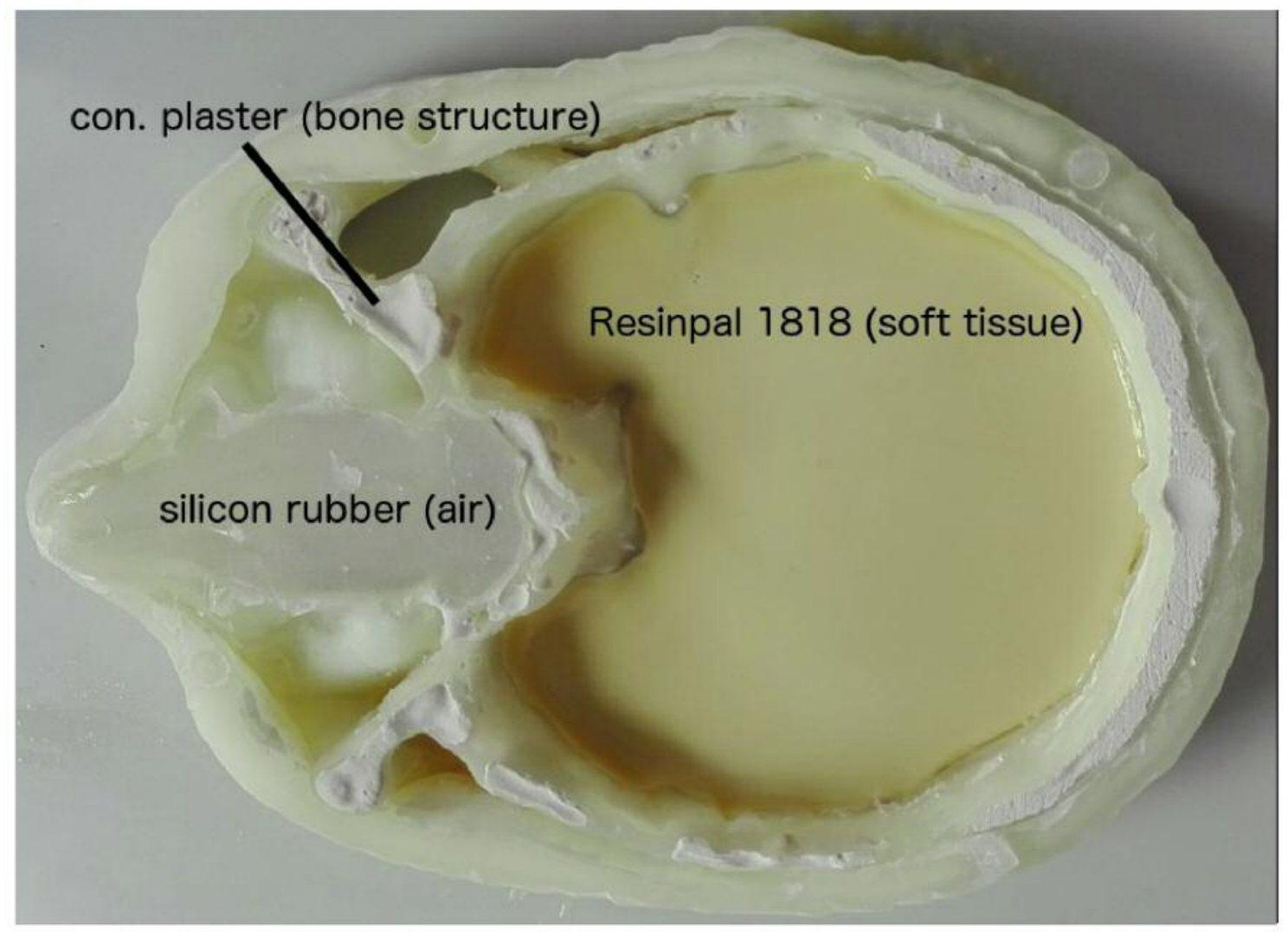

Figure 2. Combination of the printed soft tissue and bone components: Filling process of layer 6 including nasal sinuses still filled with silicone rubber. 
Table I. Overview of the materials tested with respect to the suitability for the construction of the phantom.

\begin{tabular}{|c|c|c|c|}
\hline Material & $\begin{array}{l}\text { Processing } \\
\text { time }\end{array}$ & $\begin{array}{l}\text { Range } \\
\text { of HUs }\end{array}$ & $\begin{array}{c}\text { Mean } \\
\text { HU }\end{array}$ \\
\hline Silicone rubber & $20 \mathrm{~min}$ & $253-323( \pm 35)$ & 283 \\
\hline Polyurethane casting resin & $6 \min$ & $46-82( \pm 18)$ & 54 \\
\hline Conventional silicone & Unspecified & $169-221( \pm 26)$ & 199 \\
\hline Gypsum plaster & $10 \mathrm{~min}$ & $909-1343( \pm 217)$ & 1055 \\
\hline
\end{tabular}

HU: Hounsfield units.

were generated. A Siemens Biograph mCT40 was used for generation of the CT images with the following device settings: image matrix of $512 \times 512$, tube voltage of $120 \mathrm{kV}$, tube current of $372 \mathrm{~mA}$, exposure time of $500 \mathrm{msec}$, focus size of $1.2 \mathrm{~mm}$, slice thickness of $1 \mathrm{~mm}$ and the reconstruction kernel H60f. The used MRI was a Philips Ingenia 3.0 T (Philips GmbH, Germany) and one sequence was generated: T2W_TSE, dS Head coil, matrix of $576 \times 576$, slice thickness of $4 \mathrm{~mm}$, spin echo, TR: $3000 \mathrm{msec}$, TE: $80 \mathrm{msec}$.

\section{Results}

Testing of the material. The results with respect to the testing of the materials are summarized in Table I. The silicone rubber was slightly viscous and therefore difficult to process. The mixing of the two components (rubber and crosslinking agent) resulted in numerous small air bubbles that could not be completely removed and resulted in an inhomogeneous mass. The advantage of the rubber was the processing time of only $20 \mathrm{~min}$. The mean CT value was $283 \mathrm{HU}$ (range $=253-323 \pm 35 \mathrm{HU}$ ). For an appropriate reproduction of soft tissues, this HU value was too high [usually about 50 $\mathrm{HU},(21)]$. The consistence of the polyurethane casting resin was liquid. The mixing of the two components (casting resin and hardener) showed no formation of air bubbles. The mean $\mathrm{CT}$ value was $54 \mathrm{HU}$ (range $=46-82 \pm 18 \mathrm{HU}$ ), which was equivalent to the value of $50 \mathrm{HU}$ for human soft tissue (21). At the specified mixing ratio, the gypsum plaster revealed a range of CT values between 909 and $1343( \pm 217) \mathrm{HU}$ and a mean value of $1055 \mathrm{HU}$. The calculated $\mathrm{HU}$ values correspond to those of bones in the human body (21).

Development of the phantom. The new phantom representing a prototype met the pre-defined requirements with respect to tissue-equivalence, i.e. the equivalence of the materials used for the phantom with human tissues (Table I). Moreover, the additive manufacturing of the individual structures and layers corresponded well to the generated stl-files. The attenuation properties of the different structures in the phantom corresponded in a simplified form to those of the human anatomy. Examples of CT-images are given in Figure 4.

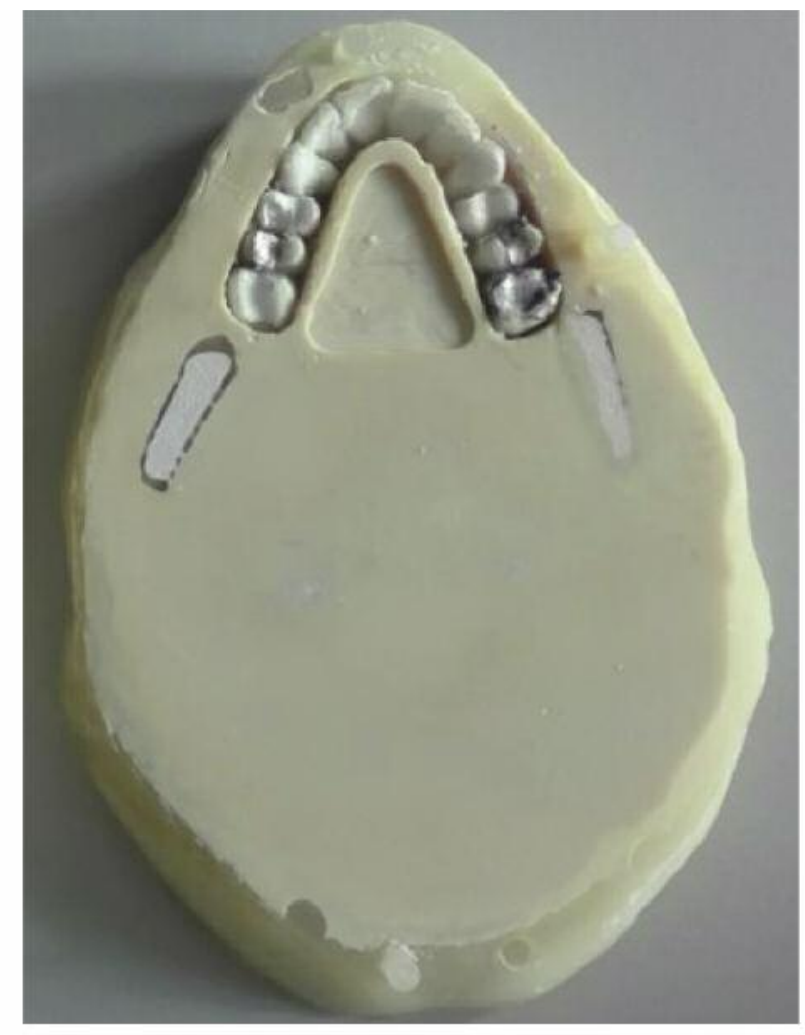

Figure 3. Slice of the upper jaw with metal implants (one molar and two premolars) corresponding to layer 8.

Moreover, as anticipated, the results of the MR-imaging measurements revealed a usable signal in the area of the polyurethane casting resin and a very weak signal in the area of the 3D-printed material and the gypsum plaster for a T2weighting (Figure 5). Thus, the phantom can be also used to contribute to scientific issues related to MR-imaging.

A few minor problems regarding the construction of the phantom were observed. Since the spaces inside the printed bone shell were sometimes too narrow or even closed, the gypsum plaster did not reach all cavities as required. This problem mainly occurred in the area of the facial skull and the temples and resulted in air bubbles in the bone area. For the vertebral bodies, a similar problem was observed. Since the proportion of the $3 \mathrm{D}$ printed part was too large, only a small area could be appropriately filled with gypsum plaster. This problem can be easily solved with a true-to-scale enlargement of the phantom.

Furthermore, the printed cylinders required for fixation of the individual layers for stabilization of the phantom broke under minor mechanical stress. This phenomenon was only observed when the base of the cylinder was parallel to the printing plate. For cylinders printed horizontally (base of the cylinder perpendicular to the printing plate) no breaks were 


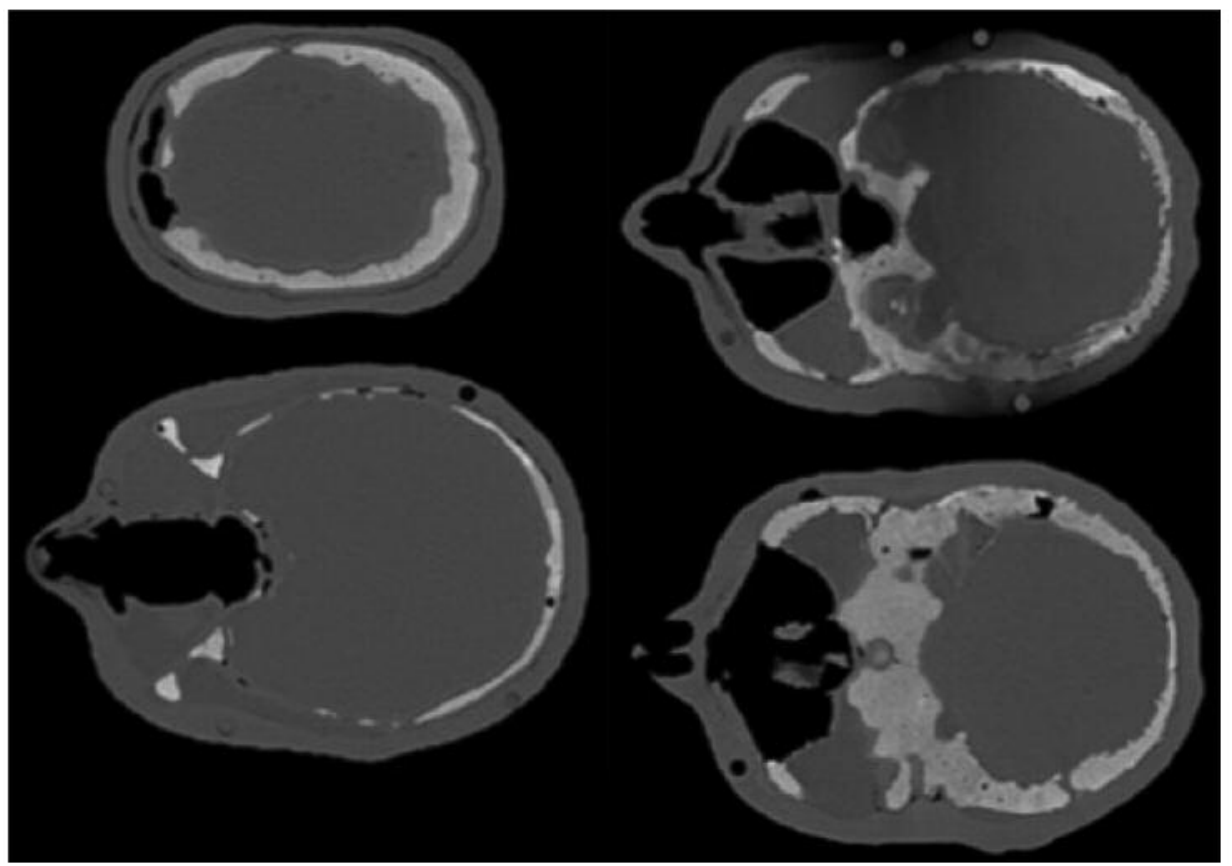

Figure 4. Selected CT layers of the phantom in the bone window showing uniform filling of the bone structure and filling with polyurethane castin resin.

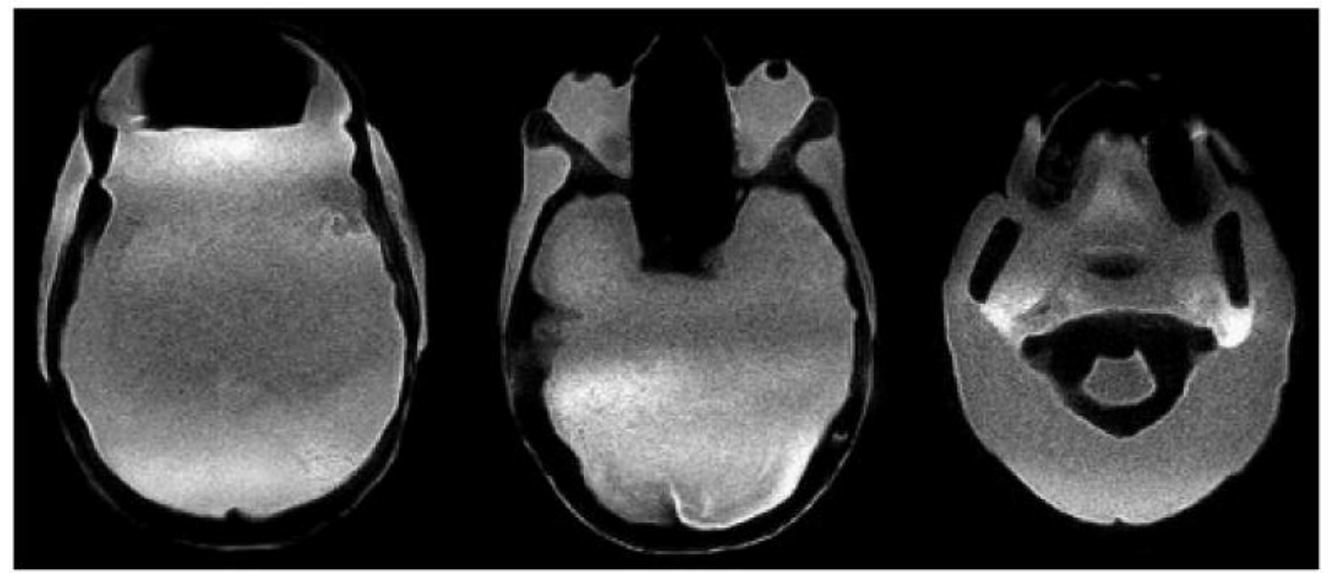

Figure 5. Transverse layers from different sections of the phantom (spin echo, T2-weighted): The 3D-printing material and gypsum plaster show a very weak signal as anticipated. The signal of the polyurethane casting resin is sufficient for imaging.

observed under mechanical stress. However, fixation of the layers using cylinders turned out to be problematic in general. When taking into account the weight of each layer of the phantom, the adhesive area of the cylinders was comparatively small. As a consequence, the cylinders became loose during the use of the phantom. This problem can also be solved easily; printed cylinders must be replaced by commercially available plastic cylinders.

\section{Discussion}

A lot of research is performed to improve the prognoses of patients with locally advanced head-and-neck cancers that are often poor (22-25). These patients are generally treated with surgery of the primary tumor and lymph nodes followed by radiotherapy plus/minus chemotherapy or with definitive radio-chemotherapy alone (2-6). These multimodal treatments 
are often associated with significant toxicities and functional restrictions $(2-7,26-28)$. The most common acute toxicities that are related to radiotherapy and radio-chemotherapy include dermatitis and oral mucositis (2-5). If interruptions of the radiotherapy course are required or the concurrent chemotherapy cannot be administered with the complete planned dose, the patients' prognoses become worse $(29,30)$. Xerostomia is a significant late morbidity that can be a consequence of surgical resection of one or both parotid glands and/or radio(chemo)therapy (2-7, 26-31). This type of late toxicity can significantly impair the patients' quality of life and lead to other late morbidities. Therefore, it is one important goal of radiotherapy of head-and-neck cancers to spare at least one parotid gland in order to reduce the risk of xerostomia. Sparing of the parotid gland(s) can be achieved with the use of modern precision techniques, namely IMRT and VMAT $(6,7)$. However, the treatment planning can be quite challenging if the patient has dental fillings or implants. In these patients, metal artefacts may not allow proper calculation and verification of the distribution of the radiation dose, and may even lead to undetected high radiation doses in the parotid glands resulting in xerostomia (8). Verification of the dose distribution may be more appropriately performed when using a phantom. Commercially available phantoms are comparatively expensive and generally not adaptable to the specific situation of an individual patient including dental fillings and implants.

Therefore, we have developed a new anthropomorphic 3Dprinted phantom specifically designed for the treatment planning in radiotherapy of head-and-neck cancers. The idea of using this type of phantom has been recently applied to other specific situations including MR-imaging issues, validation of brain SPECT analyses and end-to-end tests in ion radiotherapy but not to radiotherapy of head-an-neck cancers (32-34). The phantom developed in the present study is more cost-effective than commercially available phantoms and can be produced in every radiation oncology department if a 3D-printer is available. Moreover, its construction in layers allows fast adaptions to new situations by making changes to only one or a few layers rather than re-building the whole phantom. The new phantom met the pre-defined requirements with respect to tissue-equivalence (equivalence between the materials of the phantom and corresponding human tissues). In addition, the additive manufacturing of the individual structures and layers corresponded well to the generated stl-files. Since usable signals of the materials of the phantom on MR-imaging were found, the new phantom can also be used for MR-imaging, which is another important field of research (32). Just a few minor problems regarding the construction of the phantom were observed regarding the appropriate filling of the phantom with the gypsum plaster and the printed cylinders used for connecting the layers and for stabilization of the phantom. However, one has to be aware that this new phantom is a prototype. Fortunately, these minor problems can be easily solved and will, therefore, not affect the value of this phantom for individual treatment planning in head-and-neck cancer patients. Further development of the phantom will include dental implants and metal implants from reconstructive surgery.

In conclusion, additive manufacturing (3D-printing) proved to be suitable for the construction of a new phantom developed for treatment planning in radiotherapy of headand-neck cancers. The new phantom met the postulated requirements including the pre-defined tissue-equivalence. Particularly due to its construction in layers, it can be useful for individual treatment planning in precision-radiotherapy of head-and-neck cancers. Moreover, the phantom can be used for future scientific issues related to MR-imaging.

\section{Conflicts of Interest}

On behalf of all Authors, the corresponding Author states that there are no conflicts of interest related to this study.

\section{Authors' Contributions}

M.G., M.S., C.Z., F.C., D.R. and T.B. participated in the design of the study. M.G., M.S. and S.B. provided the data. M.G., M.S., C.Z., F.C., D.R. and T.B. performed the analyses and the interpretation of the data. M.G., M.S., C.Z. and D.R. drafted the manuscript, which was reviewed and approved in its final form by all Authors.

\section{References}

1 Siegel RL, Miller KD and Jemal A: Cancer statistics, 2019. CA Cancer J Clin 69: 7-34, 2019. PMID: 30620402. DOI: 10.3322/ caac. 21551

2 Rades D, Kronemann S, Meyners T, Bohlen G, Tribius S, Kazic N, Schroeder U, Hakim SG, Schild SE and Dunst J: Comparison of four cisplatin-based radiochemotherapy regimens for nonmetastatic stage III/IV squamous cell carcinoma of the head and neck. Int J Radiat Oncol Biol Phys 80: 1037-1044, 2011. PMID: 20638185. DOI: 10.1016/j.ijrobp.2010.03.033

3 Tribius S, Kronemann S, Kilic Y, Schroeder U, Hakim S, Schild SE and Rades D: Radiochemotherapy including cisplatin alone versus cisplatin +5 -fluorouracil for locally advanced unresectable stage IV squamous cell carcinoma of the head and neck. Strahlenther Onkol 185: 675-681, 2009. PMID: 19806333. DOI: $10.1007 / \mathrm{s} 00066-009-1992-x$

4 Bernier J, Domenge C, Ozsahin M, Matuszewska K, Lefèbvre JL, Greiner RH, Giralt J, Maingon P, Rolland F, Bolla M, Cognetti F, Bourhis J, Kirkpatrick A and van Glabbeke M; European Organization for Research and Treatment of Cancer Trial 22931: Postoperative irradiation with or without concomitant chemotherapy for locally advanced head and neck cancer. N Engl J Med 350: 1945-1952, 2004. PMID: 15128894. DOI: $10.1056 /$ NEJMoa032641

5 Cooper JS, Pajak TF, Forastiere AA, Jacobs J, Campbell BH, Saxman SB, Kish JA, Kim HE, Cmelak AJ, Rotman M, Machtay M, Ensley JF, Chao KS, Schultz CJ, Lee N and Fu KK; Radiation Therapy Oncology Group 9501/Intergroup: Postoperative 
concurrent radiotherapy and chemotherapy for high-risk squamouscell carcinoma of the head and neck. N Engl J Med 350: 19371944, 2004. PMID: 15128893. DOI: 10.1056/NEJMoa032646

6 Rades D, Fehlauer F, Wroblesky J, Albers D, Schild SE and Schmidt R: Prognostic factors in head-and-neck cancer patients treated with surgery followed by intensity-modulated radiotherapy (IMRT), 3D-conformal radiotherapy, or conventional radiotherapy. Oral Oncol 43: 535-543, 2007. PMID: 17005437. DOI: 10.1016/j.oraloncology.2006.05.006

7 Franzese C, Fogliata A, Franceschini D, Clerici E, D'Agostino G, Navarria P, Mancosu P, Tomatis S, Cozzi L and Scorsetti M: Treatment outcome and toxicity of volumetric modulated arc therapy in oropharyngeal carcinoma. Anticancer Res 36: 34513457, 2016. PMID: 27354607.

8 Akyol O, Dirican B, Toklu T, Eren H and Olgar T: Investigating the effect of dental implant materials with different densities on radiotherapy dose distribution using Monte-Carlo simulation and pencil beam convolution algorithm. Dentomaxillofac Radiol 48: 20180267, 2019. PMID: 30663343. DOI: 10.1259/dmfr.20180267

9 Stille M, Kleine M, Hagele J, Barkhausen J and Buzug TM: Augmented likelihood image reconstruction. IEEE $\mathrm{T}$ Med Imaging 35: 158-173, 2016. PMID: 26208310. DOI: 10.1109/ TMI.2015.2459764

10 Ziemann C, Stille M, Cremers F, Buzug TM and Rades D: Improvement of dose calculation in radiation therapy due to metal artifact correction using the augmented likelihood image reconstruction. J Appl Clin Med Phys 19: 227-233, 2018. PMID: 29664225. DOI: $10.1002 / \mathrm{acm} 2.12325$

11 Ziemann C, Stille M, Cremers F, Rades D and Buzug TM: The effects of metal artifact reduction on the retrieval of attenuation values. J Appl Clin Med Phys 18: 243-250, 2017. PMID: 28291909. DOI: $10.1002 / \mathrm{acm} 2.12002$

12 Micke A, Lewis DF and Yu X: Multichannel film dosimetry with non-uniformity correction. Med Phys 38: 2523-2534, 2011. PMID: 21776787. DOI: $10.1118 / 1.3576105$

13 Stromberger C, Ghadjar P, Marnitz S, Thieme AH, Jahn U, Raguse JD, Karaj-Rossbacher E, Böttcher A, Jamil B and Budach V: Comparative treatment planning study on sequential vs. simultaneous integrated boost in head and neck cancer patients: Differences in dose distributions and potential implications for clinical practice. Strahlenther Onkol 192: 1724, 2016. PMID: 26462675. DOI: 10.1007/s00066-015-0913-4

14 Brennan MT, Treister NS, Sollecito TP, Schmidt BL, Patton LL, Mohammadi K, Long Simpson L, Voelker H, Hodges JS and Lalla RV: Dental disease before radiotherapy in patients with head and neck cancer: Clinical Registry of Dental Outcomes in Head and Neck Cancer Patients. J Am Dent Assoc 148: 868-877, 2017. PMID: 29173331. DOI: 10.1016/j.adaj.2017.09.011

15 Zukauskaite R, Brink C, Hansen CR, Bertelsen A, Johansen J, Grau $\mathrm{C}$ and Eriksen JG: Open source deformable image registration system for treatment planning and recurrence $\mathrm{CT}$ scans: Validation in the head and neck region. Strahlenther Onkol 192: 545-551, 2016. PMID: 27323754. DOI: 10.1007/ s00066-016-0998-4

16 McQuaid D, Dunlop A, Nill S, Franzese C, Nutting CM, Harrington KJ, Newbold KL and Bhide SA: Evaluation of radiotherapy techniques for radical treatment of lateralised oropharyngeal cancers: Dosimetry and NTCP. Strahlenther Onkol 192: 516-525, 2016. PMID: 27295511. DOI: 10.1007/ s00066-016-0980-1
17 Nose T, Koizumi M, Yoshida K, Nishiyama K, Sasaki J, Ohnishi $\mathrm{T}$ and Peiffert D: In vivo dosimetry of high-dose-rate brachytherapy: Study on 61 head-and-neck cancer patients using radiophotoluminescence glass dosimeter. Int J Radiat Oncol Biol Phys 61: 945-953, 2005. PMID: 15708279. DOI: 10.1016/ j.ijrobp.2004.10.031

18 Karger CP, Jäkel O, Debus J, Kuhn S and Hartmann GH: Threedimensional accuracy and interfractional reproducibility of patient fixation and positioning using a stereotactic head mask system. Int J Radiat Oncol Biol Phys 49: 1493-1504, 2001. PMID: 11286858. DOI: 10.1016/s0360-3016(00)01562-5

19 Segars WP, Mahesh M, Beck TJ, Frey EC and Tsui BM: Realistic CT simulation using the $4 \mathrm{~d}$ XCAT phantom. Med Phys 35: 3800-3808, 2008. PMID: 18777939. DOI: 10.1118/ 1.2955743

20 Kikinis R, Pieper SD and Vosburgh KG: 3d slicer: A platform for subject-specific image analysis, visualization, and clinical support. In: Intraoperative imaging and image-guided therapy. Jolesz F (ed.). New York, Springer, 277-289, 2013.

21 Kalra A: Developing FE human models from medical images. In: Basic finite element method as applied to injury biomechanics. Yang KH (ed.). Cambridge, Academic Press, 389-415, 2018.

22 Arimoto S, Hasegawa T, Takeda D, Saito I, Amano R, Akashi M and Komori T: Lymphangiogenesis and lymph node metastasis in oral squamous cell carcinoma. Anticancer Res 38: 6157-6162, 2018. PMID: 30396932. DOI: 10.21873/anticanres.12968

23 Merz S, Timmesfeld N, Stuck BA and Wiegand S: Impact of lymph node yield on outcome of patients with head and neck cancer and pN0 neck. Anticancer Res 38: 5347-5350, 2018. PMID: 30194187. DOI: 10.21873/anticanres.12862

24 Bersani C, Haeggblom L, Ursu RG, Giusca SE, Marklund L, Ramqvist T, Näsman A and Dalianis T: Overexpression of FGFR3 in HPV-positive tonsillar and base of tongue cancer is correlated to outcome. Anticancer Res 38: 4683-4690, 2018. PMID: 30061236. DOI: 10.21873/anticanres.12774

25 Kuwahara T, Takahashi H, Sano D, Matsuoka M, Hyakusoku H, Hatano T, Hiiragi Y and Oridate N: Fibrinogen and neutrophil-tolymphocyte ratio predicts survival in patients with advanced hypopharyngeal squamous cell carcinoma. Anticancer Res 38: 5321-5330, 2018. PMID: 30194184. DOI: 10.21873/anticanres. 12859

26 Narvaez C, Doemer C, Idel C, Setter C, Olbrich D, Ujmajuridze Z, Carl JH and Rades D: Radiotherapy related skin toxicity (RAREST-01): Mepitel ${ }^{\circledR}$ film versus standard care in patients with locally advanced head-and-neck cancer. BMC Cancer 18 : 197, 2018. PMID: 29454311. DOI: 10.1186/s12885-018-4119-x

27 Rades D, Narvaez CA, Splettstößer L, Dömer C, Setter C, Idel C, Ribbat-Idel J, Perner S, Bartscht T, Olbrich D, Schild SE and Carl J: A randomized trial (RAREST-01) comparing Mepitel ${ }^{\circledR}$ film and standard care for prevention of radiation dermatitis in patients irradiated for locally advanced squamous cell carcinoma of the head-and-neck (SCCHN). Radiother Oncol 139: 79-82, 2019. PMID: 31431372. DOI: 10.1016/j.radonc.2019.07.023

28 Chen LY, Huang CC, Tsou YA, Bau DT and Tsai MH: Prognostic factor of severe complications in patients with hypopharyngeal cancer with primary concurrent chemoradiotherapy. Anticancer Res 35: 1735-1741, 2015. PMID: 25750336.

29 Rades D, Stoehr M, Kazic N, Hakim SG, Walz A, Schild SE and Dunst J: Locally advanced stage IV squamous cell carcinoma of the head and neck: impact of pre-radiotherapy hemoglobin level 
and interruptions during radiotherapy. Int J Radiat Oncol Biol Phys 70: 1108-1114, 2008. PMID: 17905528. DOI: 10.1016/j.ijrobp.2007.07.2380

30 Fesinmeyer MD, Mehta V, Blough D, Tock L and Ramsey SD: Effect of radiotherapy interruptions on survival in medicare enrollees with local and regional head-and-neck cancer. Int J Radiat Oncol Biol Phys 78: 675-681, 2010. PMID: 20133084. DOI: $10.1016 /$ j.jjrobp.2009.08.004

31 Rades D, Stoehr M, Meyners T, Bohlen G, Nadrowitz R, Dunst J, Schild SE, Wroblewski J, Albers D, Schmidt R, Alberti W and Tribius S: Evaluation of prognostic factors and two radiation techniques in patients treated with surgery followed by radio(chemo)therapy or definitive radio(chemo)therapy for locally advanced head-and-neck cancer. Strahlenther Onkol 184: 198-205, 2008. PMID: 18398584. DOI: 10.1007/s00066-008$1825-3$

32 Wood S, Krishnamurthy N, Santini T, Raval SB, Farhat N, Holmes JA and Ibrahim TS: Design and fabrication of a realistic anthropomorphic heterogeneous head phantom for MR purposes. PLoS One 12: e0183168, 2017. PMID: 28806768. DOI: 10.1371/journal.pone .0183168
33 Negus IS, Holmes RB, Jordan KC, Nash DA, Thorne GC and Saunders M: Technical note: Development of a 3D printed subresolution sandwich phantom for validation of brain SPECT analysis. Med Phys 43: 5020, 2016. PMID: 27587032. DOI: 10.1118/1.4960003

34 Gallas RR, Hünemohr N, Runz A, Niebuhr NI, Jäkel O and Greilich S: An anthropomorphic multimodality (CT/MRI) head phantom prototype for end-to-end tests in ion radiotherapy. $\mathrm{Z}$ Med Phys 25: 391-399, 2015. PMID: 26189015. DOI: 10.1016/j.zemedi.2015.05.003
Received October 29, 2019

Revised November 4, 2019

Accepted November 5, 2019 